\title{
The relationship between management strategies for menopausal symptoms and women's decision making styles during menopausal transition
}

\author{
Narjes Bahri ${ }^{1}$, Moosa Sajjadi², Leila Sadeghmoghadam³ \\ ${ }^{1}$ Department of Midwifery, Faculty of Medicine, Social Development and Health Promotion Center, Gonabad University \\ of Medical Sciences, Gonabad, IR Iran \\ ${ }^{2}$ Department of Medical Surgical Nursing, School of Nursing, Social Development and Health Promotion Center, Gonabad \\ University of Medical Sciences, Gonabad, IR Iran \\ ${ }^{3}$ Department of Nursing, School of Nursing, Social Development and Health Promotion Center, Gonabad University \\ of Medical Sciences, Gonabad, IR Iran
}

\begin{abstract}
Introduction: Considering the importance of identifying the factors affecting women's decision making process about the management of menopausal symptoms, this study was conducted with the aim of investigating the relation between decision making styles and women's chosen options for management of menopausal symptoms.

Material and methods: This cross-sectional study was conducted from May 2016 to July 2018 in Gonabad, north east of Iran. Using the cluster sampling method 473 women between 45 and 60 years old were recruited to the study. Data were collected using a demographic questionnaire, a menopause symptom treatment options questionnaire, the Menopause Rating Scale and the Decision Making Styles Questionnaire. The data analysis was conducted using SPSS software version 16 as well as descriptive and analytical statistics; a $p$-value of $<0.05$ was considered as statistically significant.

Results: The mean age of participants was $51.6 \pm 4.6$ years old and the majority of them ( $85.5 \%)$ were housewives. The most popular menopause symptom treatment option was hormone replacement therapy. The majority of participants (45.4\%, 228 people) used an avoidant decision making style. There was no statistically significant difference between menopausal symptom treatment options and decision making styles type $(p=0.525)$. There was a statistically significant difference between severity of menopausal symptoms and type of decision making style $(p=0.003)$.

Conclusions: The findings showed that there was no significant relation between the selected method to manage menopausal symptoms and women's decision making styles. It is recommended that this study be conducted on a population that has greater access to all menopausal symptom treatment options.
\end{abstract}

Key words: decision making style, menopause, estrogen replacement therapy, postmenopause.

\section{Introduction}

The universal trend of population aging and increase in the population of over 50 years old women in developed and under-developed countries has made women's health during the menopausal transition an important health issue of the present era [1, 2]. The World Health Organization (WHO) has predicted the number of postmenopausal women worldwide to reach 1.2 billion by 2030 [3]. Iran also like many developing countries is experiencing considerable population and epidemiologic changes and according to some statisti- cal reports, it is expected that by 2020 , about 5 million postmenopausal women will live in Iran [4].

Management of menopausal symptoms and facing the related complications is one of the great challenges of the transition to menopause among women. Although these symptoms arise from physiologic changes [5], they are very annoying in some cases and in addition to reducing the quality of life they lead to the referral of a considerable number of women to the doctor in menopausal transition. Management of menopausal symptoms is possible through a wide range of methods including hormone replacement therapy, acupressure, 
herbal compounds, acupuncture, massage therapy, yoga, and lifestyle changes such as sports and diets [6-9].

Although it seems that considering this wide range of treatment options, the women do not have a problem with management of the menopausal symptoms, the reality is that management of these symptoms is associated with several challenges. The most important challenge is the ambiguity about the safety of these options, especially hormone therapy. Although at first it was thought that hormone therapy can prevent osteoporosis and decrease the risk of cardiovascular diseases, the early termination of the great research project of WHI in 2001 which happened due to increased risk of breast cancer and cardiovascular diseases in women, created important challenges for the safety and effectiveness of hormone therapy [10]. On the other hand, despite the huge popularity of complementary and alternative therapies, the results of the studies have not proved the definite impacts of these methods [11-13]. This has complicated the menopausal symptoms management decision making process. This complication arise from the different nature of menopause in comparison with other health topics in addition to the existing challenges related to hormone replacement therapy and the uncertainty of other methods such as alternative and complementary therapies. Also, the health care providers in the process of decision making on management of menopausal symptoms are facing with adult persons, who have their certain complexity [14].

The ability of making effective decisions is a very important skill in life and work. But according to Scott and Bruce (1995), in comparison to the task and context of the decision, insufficient emphasis is put on the features of a decision maker affecting the results of the decision. Lately, researchers have been focusing on the features of the decision maker, so a huge amount of literature is arising on the basis of decision-making models [15, 16].

Decision making refers to the process of making a smart judgment to choose a suitable option in the presence of several complex options [17]. Scott and Bruce focused on internal characteristics and individual differences of people in their study on people's decision making styles and factors affecting them, based on which they introduced five decision making styles: rational, intuitive, dependent, spontaneous and avoidant [18].

The decision making process and the way of choosing different treatment options during the menopausal transition have received more attention in recent years [19]. Today, it is evident that women in the menopausal transition period have the right to decide on their symptom management and considerations should be given to the women's decision making process in management of menopausal symptoms and the factors affecting this process.

The decision making styles of Scott and Bruce in patients' choices have been studied and Fischer et al. stated in this regard that decision making styles of rational, intuitive, dependent and avoidant are highly de- pendent on care fields [20]. The results of the previous study showed that factors such the amount of information on menopause, type and source of information, validity and availability of information uncertainty about menopause and the psychological stresses caused by menopause symptoms interfere with the decision making process for menopause symptom treatment [21], which can limit the decision making style implementation of a woman. On the other hand, making decisions in uncertain situations mostly results in using heuristic decision making patterns since these patterns will reduce the complexity of decision making [22]. According to this information, it can be stated that rational and intuitive decision making styles are important aspects of this process which should be paid attention to in deciding on management of menopausal symptoms. Also, dependence on others plays an important role in the decision making process, since social networks and health care providers support women's choices for management of menopausal symptoms and even direct these choices in some cases and sometimes are a source of information on this subject $[21,23]$.

Considering the importance of identifying the factors affecting women's decision making process about the management of menopausal symptoms, this study was conducted with the aim of investigating the relation between decision making styles and women's chosen options for management of menopausal symptoms.

\section{Material and methods}

\section{Study design}

The protocol of this cross-sectional study is approved by the Research Council if Gonabad University of Medical Sciences (Registration code: p/3/614). The STROB checklist is utilized in the study reporting [24].

\section{Participants and setting}

The study was conducted from May 2016 to July 2018 in Gonabad, north east of Iran. Gonabad is a small and relatively traditional city in Chorasan-e Rezawi province and $13^{\text {th }}$ in the population ranking of this province.

The participants were women between 45 and 60 years old whose menopause occurred naturally and did not have a premature menopause. These women did not have a history of hysterectomy or ovariectomy and in addition to the desire to participate in the study, did not have any specific contraindications to use different options of menopausal symptoms.

\section{Sample size and sampling method}

The sample size was calculated as 457 considering the safety margin of $95 \%$ and accuracy of $0.02 \%$, using 
Naseh et al.'s study [25] in which the frequency of using hormone therapy in postmenopausal women was reported as $11.5 \%$. Considering the probability of improper questionnaire filling and drop out, the final sample size was 500 people.

The cluster sampling method was used in this study. That way, three community health centers of Gonabad city were chosen as clusters and further a sampling framework including women between 45 and 60 years was obtained using the household registration offices of each center. The participants were chosen from this list using a systematic random sampling method.

\section{Study instruments}

Data collection was conducted using four questionnaires: a demographic questionnaire, a menopause symptom treatment options questionnaire, the Menopause Rating Scale (MRS) and the general Scott and Bruce Decision Making Styles Questionnaire (DMSQ).

The demographic questionnaire included questions on personal and fertility profiles of participants such as age; jobs; marital status; husband's education; husband's job; age of menarche; number of pregnancies; number of children; the last menstruation; regularity of menstrual cycles.

The menopause symptom treatment options questionnaire was designed by the researchers to investigate using or not using the options related to menopause symptoms and the type of therapies being used. Questions concerned different options of menopause treatment and in the case of choosing each option, the participants answered more detailed questions such as consumption level, consumption frequency, satisfaction with the method, etc.

The MRS questionnaire is a valuable international tool for investigating menopause symptoms which is used in many clinical and epidemiological studies to determine the frequency and intensity of the symptoms in middle-aged women [26-29]. These tools include 11 symptoms related to menopause in three fields of physical (4 questions), mental (4 questions) and urogenital (3 questions). In the fields of physical issues, factors such as flushing and night sweats, heart disease, sleep disorders, muscle and joint pains, and in the psychological field factors including depression, nervousness, anxiety, memory weakness, and lack of concentration are investigated. In the urogenital field, questions related to decreased sexual desire and satisfaction, urinary problems, dryness and irritation of the vagina are posed. These questions are assessed with a 5-point Likert scale. In this questionnaire, the options "not suffering from" and "very severe" are designated with scores of 1 and 5, respectively, and the total scores of the MRS questionnaire are in the range of 11 to 55 . A lower total score of the MRS or the score related to each of the fields or the score related to the questions of each field shows less intense menopause symptoms [27].

The DMSQ is validated for assessing people's decision making type using the design factor analysis method described by Scott and Bruce in 1995 [18]. This questionnaire consists of 25 questions measuring the five decision making styles of rational, intuitive, avoidance, dependent and spontaneous. Scoring each statement was conducted based on a five-point Likert scale from "Completely agree" to "Completely disagree" and in the domain of 1 to 5 . Each style has 5 questions. Questions $14,6,21,19$, and 23 are associated with avoidant decision making style, questions $1,3,12,16$, and 17 with intuitive style, questions $4,7,13,11$, and 25 with rational style, questions $3,5,10,18$, and 22 with dependent style and questions 8, 9, 15, 20 and 24 with spontaneous decision making style. The total score of the questionnaire is between 25 and 125 and in each subscale is between 5 and 25. A higher score in each subscale shows that it is the dominant decision making style. Scott and Bruce reported the reliability of this questionnaire using Cronbach's $\alpha$ values from 0.68 to 0.94 [18]. The reliability of this questionnaire is reported in another study conducted in England with Cronbach's $\alpha$ of 0.67 to 0.87 [30]. In Iran also Hadizade Moghadam and Tehrani have done psychometry of this questionnaire and reported its reliability using Cronbach's $\alpha$ of 0.71 [31], and another study on Iranian students reported the reliability factor with the Cronbach's $\alpha$ of 0.75 for the total scale [32].

\section{Collecting dato}

For data collection, after selecting the participants of the study based on the previously mentioned method, the researchers contacted them and in case of certainty of their inclusion criteria provided them with a brief description of the study aims and invited them to participate in it. The places of filling in the questionnaires were based on the participants' preferences, in their home or the health center. Before completing the questionnaires, participants signed the written consent form and then answered the questions in the presence of the researcher and if necessary, the questionnaires were completed by the interview method. At the end, to acknowledge participation in the study, an educational package on menopause symptom treatment was gifted to participants.

\section{Statistical analysis}

The data analysis was conducted using SPSS software version 16 as well as descriptive and analytical statistics. For evaluation of demographic data, descriptive statistics such as mean, standard deviation and distribution of absolute and relative abundance were used 
and the results were set in tables and graphs and then to analyze these results, analytical statistics were used. $P$ values of $<0.05$ were considered statistically significant.

\section{Results}

27 participants were excluded and a total of 473 women completed the study. The majority of the participants (85.5\%) were housewives and their mean age was $51.64 \pm 4.62$. Among the participants, 445 (87.1\%) were married and 56 (12.7\%) were widows. The average number of their children was $3.82 \pm 1.75$ and they had completed $6.81 \pm 4.26$ years of schooling. 313 (61.3\%) of them were menopausal, and in the women who were not menopausal, the mean and SD of the last menstrual period was $37.99 \pm 45.62$ months ago. The withdrawal method was the most common (45.6\%) and vasectomy was the least contraceptive method (2.4\%).

The results of the MRS questionnaire showed that 319 (74\%) of the participants suffered from mild symptoms, 109 (25.3\%) from moderate and 3 (0.7\%) from severe symptoms, while the total score of this questionnaire was $21.97 \pm 6.69$. Table 1 presents the results of self-assessment of the participants' information on the options of management of menopausal symptoms.

The most popular menopause symptom treatment option was hormone replacement therapy (201 women, 58.8\%). 33\% (113 participants) opted for herbal therapy, 3.5\% (12 participants) preferred physical activity and $2.9 \%$ showed preference for diet change. Acupuncture, reflexology and yoga received no application request.
The decision making style assessment of the participants showed that $10.8 \%$ (54 participants) used rational style, $2.6 \%$ (13 participants) intuitive style, $12.9 \%$ (65 participants) dependent style, and 45.4\% (228 participants) used avoidant decision making style.

With regard to the main aim of the study, the outcomes of the $\chi^{2}$ test showed no statistically significant difference between menopausal symptom treatment options and decision making styles type $(p=0.525)$. For instance, $44.7 \%$ of the participants had avoidant decision making style while opting for hormonal replacement therapy (Table 2).

Furthermore, the results revealed a statistically significant difference between severity of menopausal symptoms and type of decision making style $(p=0.003)$ (Table 3).

Other results revealed an indirect significant relation between menopausal symptoms and spontaneous and avoidance decision making style scores $(p=0.002$ and $p<0.0001$ respectively).

Furthermore, the results showed a statistically significant difference between decision making style and education level $(p<0.0001)$.

\section{Discussion}

The main results of the present study showed no significant relation between the selected method to treat menopausal symptoms and women's decision making styles. According to the current literature, it seems that similar studies have not been conducted

Table 1. Participants' self-assessment of their knowledge about treatment options of menopausal symptoms

\begin{tabular}{lccc}
\hline Knowledge & $\begin{array}{c}\text { Low } \\
(\%)\end{array}$ & $\begin{array}{c}\text { Moderate } \\
n(\%)\end{array}$ & $\begin{array}{c}\text { High } \\
n(\%)\end{array}$ \\
\hline Hormonal replacement therapy & $431(84.3)$ & $74(14.5)$ & $6(1.2)$ \\
\hline Acupressure & $482(94.3)$ & $27(5.3)$ & $2(0.4)$ \\
\hline Acupuncture & $485(94.9)$ & $26(1 / .5)$ & $0(0.0)$ \\
\hline Reflexology & $475(94.9)$ & $34(6.7)$ & $1(0.2)$ \\
\hline Yoga & $460(90.0)$ & $50(9.8)$ & $1(0.2)$ \\
\hline Diet modification & $408(79.8)$ & $89(17.4)$ & $12(2.3)$ \\
\hline Physical activity & $408(79.8)$ & $91(17.8)$ & $12(2.3)$ \\
\hline Herbal remedies & $384(75.1)$ & $113(22.1)$ & $14(2.7)$ \\
\hline
\end{tabular}

Table 2. Relation between treatment option of menopausal symptoms and type of decision making styles

\begin{tabular}{lccc}
\hline Decision making style & $\begin{array}{c}\text { Hormonal replacement therapy } \\
n(\%)\end{array}$ & $\begin{array}{c}\text { Herbal remedies } \\
n(\%)\end{array}$ & $\begin{array}{c}\text { Other treatment options } \\
n(\%)\end{array}$ \\
\hline Rational decision making style & $19(35.2)$ & $13(24.1)$ & $22(40.7)$ \\
\hline Intuitive decision making style & $4(30.8)$ & $2(15.4)$ & $7(53.8)$ \\
\hline Dependent decision making style & $25(38.5)$ & $13(20)$ & $27(41.5)$ \\
\hline Spontaneous decision making style & $49(34.5)$ & $38(26.8)$ & $55(38.7)$ \\
\hline Avoidant decision making style & $49(34.5)$ & $38(26.8)$ & $55(38.7)$ \\
\hline$\chi^{2}=7.105, d f=8, p=0.525$ & & &
\end{tabular}


Table 3. Relation between severity of menopausal symptoms and type of decision making styles

\begin{tabular}{|c|c|c|c|c|}
\hline Severity of menopausal symptoms & $\begin{array}{l}\text { Mild } \\
n(\%)\end{array}$ & $\begin{array}{c}\text { Moderate } \\
n(\%)\end{array}$ & $\begin{array}{c}\text { Severe } \\
n(\%)\end{array}$ & $\begin{array}{c}\text { Result of Pearson } \\
\text { correlation test }\end{array}$ \\
\hline Rational decision making style & $30(56.2)$ & $16(34.8)$ & $0(0.0)$ & $\begin{array}{c}r=011 \\
p=0.818\end{array}$ \\
\hline Intuitive decision making style & $10(83.2)$ & $2(16.7)$ & $0(0.0)$ & $\begin{array}{l}r=-0.056 \\
p=0.265\end{array}$ \\
\hline Dependent decision making style & $28(54.9)$ & $21(41.2)$ & $2(3.9)$ & $\begin{array}{l}r=-0.96 \\
p=0.051\end{array}$ \\
\hline Spontaneous decision making style & $94(81.7)$ & $21(18.3)$ & $0(0.0)$ & $\begin{array}{l}r=-0.225 \\
p<0.0001\end{array}$ \\
\hline Avoidant decision making style & $154(76.6)$ & $46(22.9)$ & $1(0.5)$ & $\begin{array}{l}r=-0.175 \\
p=0.002\end{array}$ \\
\hline
\end{tabular}

and therefore it is not possible to compare the results of the present study with similar ones.

Nevertheless, reviewing the existing knowledge shows that decision making styles are investigated in other fields of medical and behavioral sciences. For instance, Shaghaghi et al. investigated the relations between decision making styles and emotional attachment styles of addicted and non-addicted men. The results showed that the rational decision making style of addicted men was significantly more frequent than in non-addicted men, but there was no statistically significant difference in other decision making styles. Moreover, there was a direct and significant relation between the rational decision making style and learned helplessness [33]. In another study, a significant negative relation between self-monitoring dimension sensitivity to expressive reactions of others and spontaneous and dependent decision making styles was reported [34]. Another study with the aim of investigating the relation between health literacy and decision making styles for complex antithrombotic therapy among older multimorbid adults reported that those with inadequate functional health literacy were more likely to prefer passive rather than active decision making styles even after controlling for age, education and numeracy. Also it was reported in this study that $40 \%$ of patients preferring passive styles had adequate functional health literacy and these patients were much more likely to change their preferences to more active styles if their physician "was more supportive or encouraged participation." An interesting inference from the results of this study is that when the patients are encouraged and supported by doctors, there exists a possibility of passive decision making styles changing to active ones [35].

It is worth mentioning that the results of the present study suggested that the women were not entirely aware of or had very little information on some menopausal symptom treatment options such as acupuncture, yoga, acupressure, and reflexology, and therefore in practice these methods did not enter the decision making process of the participants, and consequently only the three options of hormonal replacement, herbal compounds and other methods (including diet modification) entered the analysis, since the other options did not have any users among the participants. Therefore, it seems that if this study were conducted in a population with the possibility of using all the methods almost equally, different results would be obtained.

The results of the present study in investigating the decision making styles of the participants showed that avoidant, spontaneous, dependent, rational and intuitive styles have respectively been the most prevalent. By comparing the results of the present study with similar ones, it seems that the dominant decision making style is highly dependent on the target population. Delaney et al. reported almost similar results. In their study, which was conducted on 1075 American citizens, spontaneous and dependent decision making styles had the highest frequency [15]. In Loo et al.'s study, the rational, dependent and intuitive decision making styles had the highest frequency among management undergraduate students [16]. In Baiocco et al.'s study which was conducted on a group of young Italian students, rational, intuitive and dependent decision making styles had the highest frequency, in that order [36].

Investigating more details of the present study showed that the dominant decision making styles in users of hormone replacement therapy and herbal compounds were avoidant and spontaneous. It is noteworthy in this regard that overall, the majority of the participants, i.e. $73.7 \%$, had avoidant and spontaneous decision making styles and the frequency of the decision making styles among the participants was low. Therefore, it can be stated that the higher prevalence of avoidant and spontaneous decision making styles in users of hormone replacement therapy and herbal compounds is a function of decision making styles' frequency in the participants.

The most important limitation of the present study was that the women were not aware of different menopausal symptom treatment options in the context and the time of the study, and also several options for this 
treatment were not available to the women and it greatly affects the women's decision making process. It is recommended that this study be conducted on a population that has greater access to all menopausal symptom treatment options.

\section{Conclusions}

In this study there was no significant relation between the selected method to manage menopausal symptoms and women's decision making styles. It is recommended that this study be conducted on a population that has greater access to all menopausal symptom treatment options.

\section{Acknowledgements}

This research was supported by a grant from the Gonabad University of Medical Sciences (grant number: $\mathrm{p} / 3 / 614)$.

\section{Disclosure}

The authors report no conflict of interest.

\section{References}

1. Mohammadpour A, Sadeghmoghadam L, Shareinia $\mathrm{H}$, et al. Investigating the role of perception of aging and associated factors in death anxiety among the elderly. Clin Interv Aging 2018; 13: 405-410.

2. Yazdkhasti M, Tourzani ZM, Roozbeh N, et al. The association between diabetes and age at the onset of menopause: a systematic review protocol. Syst Rev 2019; 8: 80.

3. Stephenson K, Neuenschwander PF, Kurdowska AK. The effects of compounded bioidentical transdermal hormone therapy on hemostatic, in flammatory, immune factors; cardiovascular biomarkers; quality-of-life measures; and health outcomes in perimenopausal and postmenopausal women. Int J Pharm Compd 2013; 17: 74-85.

4. Bahri N, Latifnejad Roudsari R, Azimi Hashemi M. "Adopting self-sacrifice": how Iranian women cope with the sexual problems during the menopausal transition? An exploratory qualitative study. J Psychosom Obstet Gynaecol 2017; 38: 180-188.

5. Lumsden MA, Sassarini J. The evolution of the human menopause. Climacteric 2019; 22: 111-116.

6. Bolaños R, Del Castillo A, Francia J. Soy isoflavones versus placebo in the treatment of climacteric vasomotor symptoms: systematic review and meta-analysis. Menopause 2010; 17: 660-666.

7. Hill DA, Crider M, Hill SR. Hormone Therapy and Other Treatments for Symptoms of Menopause. Am Fam Physician 2016; 94: 884-889.

8. McGuire A, Anderson D. Yoga and acupuncture versus "sham" treatments for menopausal hot flashes: how do they compare? Menopause 2019; 26: 337.

9. Avis NE, Levine BJ, Danhauer S, Coeytaux RR. A pooled analysis of three studies of nonpharmacological interventions for menopausal hot flashes. Menopause 2019; 26: 350-356.

10. Suter E, Verhoef M, Bockmuehl C, et al. Women's approaches to evaluating complementary and alternative therapies for menopausal symptoms. Can Fam Physician 2007; 53: 84-90.

11. Wang Y, Lou XT, Shi YH, et al. Erxian decoction, a Chinese herbal formula, for menopausal syndrome: An updated systematic review. J Ethnopharmacol 2019; 234: 8-20.
12. Befus D, Coeytaux RR, Goldstein KM, et al. Management of Menopause Symptoms with Acupuncture: An Umbrella Systematic Review and Meta-Analysis. J Altern Complement Med 2018; 24: 314-323.

13. Nelson HD, Vesco KK, Haney E, et al. Nonhormonal therapies for menopausal hot flashes: systematic review and meta-analysis. JAMA 2006; 295: 2057-2071.

14. Hunter MS, O'Dea I, Britten N. Decision-making and hormone replacement therapy: a qualitative analysis. Soc Sci Med 1997; 45: 1541-1548.

15. Delaney R, Strough J, Parker AM, de Bruin WB. Variations in DecisionMaking Profiles by Age and Gender: A Cluster-Analytic Approach. Pers Individ Dif 2015; 85: 19-24.

16. Loo R. A psychometric evaluation of the general decision-making style inventory. Pers Individ Diff 2000; 29: 895-905.

17. MeSH database: Decision Making. https://www.ncbi.nlm.nih.gov/ mesh/?term=decision+making (access: Mar 2, 2019).

18. Scott SG, Bruce RA. Decision-making style: The development and assessment of a new measure. Educ Psychol Meas 1995; 55: 818-831.

19. Walter F, Emerya JD, Rogers M, Britten N. Women's views of optimal risk communication and decision making in general practice consultations about the menopause and hormone replacement therapy. Patient Educ Couns 2004; 53: 121-128.

20. Fischer S, Soyez K, Gurtner S. Adapting Scott and Bruce's General Decision-Making Style Inventory to Patient Decision Making in Provider Choice. Med Decis Making 2015; 35: 525-532.

21. Carpenter J, Byrne MM, Studts J. Factors related to menopausal symptom management decisions. Maturitas 2011; 70: 10-15.

22. Kahneman D. A perspective on judgment and choice: mapping bounded rationality. Am Psychol 2003; 58: 697-720.

23. Theroux R, Taylor K. Women's decision making about the use of hormonal and nonhormonal remedies for the menopausal transition. J Obstet Gynecol Neonatal Nurs 2003; 32: 712-723.

24. STROBE Statement - Checklist of items that should be included in reports of cross-sectional studies. https://www.strobe-statement.org/ fileadmin/Strobe/uploads/checklists/STROBE_checklist_v4_cross-sectional.pdf. (access: 9 Apr 2019).

25. Naseh N, Khazaei Z, Ghanbarzadeh N. Evaluation of knowledge, attitude and practice of menopausal women about HRT in BirJand. J Birjand University Med Sci 2003; 10: 35-39.

26. Monterrosa-Castro A, Portela-Buelvas K, Oviedo HC, et al. Differential Item Functioning of the Psychological Domain of the Menopause Rating Scale. Biomed Res Int 2016; 2016: 8790691.

27. Gazibara T, Dotlic J, Kovacevic N, et al. Validation of the Menopause Rating Scale in Serbian language. Arch Gynecol Obstet 2015; 292: 1379-1386.

28. Khatoon A, Husain S, Husain S, Hussain S. An Overview of Menopausal Symptoms Using the Menopause Rating Scale in a Tertiary Care Center. J Midlife Health 2018; 9: 150-154.

29. Blümel JE, Arteaga E, Parra J, et al. Decision-making for the treatment of climacteric symptoms using the Menopause Rating Scale. Maturitas 2018; 111: 15-19.

30. Spicer DP, Sadler-Smith E. An examination of the general decision making style questionnaire in two UK samples. J Manage Psych 2005; 20: 137-149.

31. Hadizadeh Moghadam A, Tehrani M. Study of the relationship between decision making styles of managers in governmental organization. Governmental Manag 2008; 1: 123-138.

32. Zare H, Aerab Sheibani KH. Reliability and Validity of Decision Making Styles Questionnaire in Iranian Students. Psychol Res 2012; 28: 112.

33. Shaghaghy F, Saffarinia M, Iranpoor M, Soltanynejad A. The Relationship of Decision-Making Styles and Attributional Styles in Addicted and Nonaddicted Men. Addict Health 2011; 3: 99-104.

34. Geisler M, Allwood CM. Relating Decision-Making Styles to Social Orientation and Time Approach. J Behav Decis Mak 2018; 31: 415-429.

35. Naik AD, Street RL Jr, Castillo D, Abraham NS. Health Literacy and Decision Making Styles for Complex Antithrombotic Therapy Among Older Multimorbid Adults. Patient Educ Couns 2011; 85: 499-504.

36. Baiocco R, Laghi F, D’Alessio M. Decision-making style among adolescents: relationship with sensation seeking and locus of control. J Adolesc 2009; 32: 963-976. 